\title{
PENGARUH EFIKASI DIRI DAN DUKUNGAN SOSIAL TERHADAP OPTIMISME MENGHADAPI DUNIA KERJA SISWA KELAS XII SMK IPTEK SANGGA BUANA PANGKALAN KARAWANG
}

\author{
Winda Sri Pramesti Nugraha ${ }^{1}$, Cempaka Putrie Dimala ${ }^{2}$, dan Arief Rahman \\ Hakim $^{3}$ \\ Email:Ps16.Windanugraha@mhs.ubpkarawang.ac.id
}

Fakultas Psikologi Universitas Buana Perjuangan Karawang

\begin{abstract}
The world of work comprises a group of individuals who perform work activities both within both cooperation and organizations. Currently, the difficulty of obtaining a job in this era of globalization remains a hot topic that is very troubling for Vocational high school graduates having no work experience. Optimism is defined as an overall view of seeing all good things and being able to think positively and view bad events as only temporary. This study aims to determine the effect of self-efficacy and social support on optimism in facing the world of work challenges for the class XII students of SMK IPTEK Sanggabuana Pangkalan Karawang. This study will use quantitative methods with the total population of class XII 270 students and sampling using a sampling quota of 152 students. The results of this hypothesis test will determine the effect of self-efficacy and social support on optimism in facing the world of work of class XII students of SMK IPTEK Sanggabuana Pangkalan Karawang (name of school) with a total value of $51.3 \%$ and a significant value of 0.000 , smaller than $0.05(p<0.05)$.
\end{abstract}

Keywords: Self-Efficacy, Social Support, Optimism in Facing the World of Work

\begin{abstract}
Abstrak
Dunia kerja merupakan dunia tempat sekumpulan individu dalam melakukan suatu aktivitas kerja baik di dalam perusahaan maupun organisasi. Sulitnya mendapatkan pekerjaan di masa globalisasi ini menjadi topik hangat yang sangat meresahkan bagi lulusan-lulusan SMK yang memang belum memiliki pengalaman dalam bekerja. Optimisme merupakan suatu pandangan secara menyeluruh melihat semua hal yang baik dan bisa berpikir secra positif serta berpikir peristiwa buruk hanya bersifat sementara. Dalam penelitian ini bertujuan untuk mengetahui pengaruh efikasi diri dan dukungan sosial terhadap optimisme menghadapi dunia kerja siswa kelas XII SMK IPTEK Sanggabuana Pangkalan Karawang. Penelitian ini menggunakan metode kuantitatif dengan jumblah populasi keseluruhan kelas XII 270 siswa penggambilan sampel menggunakan sampling kuota yang berjumlah 152 siswa. Hasil uji hipotesis bahwa terdapat pengaruh efikasi diri dan dukungan sosial terhadap optimisme menghadapi dunia kerja siswa kelas XII SMK IPTEK Sanggabuana Pangkalan Karawang dengan jumlah nilai sebesar 51,3\% dan nilai signifikan sebesar 0,000 lebih kecil dari $0,05(\mathrm{p}<0,05)$.
\end{abstract}

Kata Kunci: Efikasi Diri, Dukungan Sosial, Optimisme Menghadapai Dunia Kerja. 


\section{PENGANTAR}

Dunia kerja merupakan dunia tempat sekumpulan individu dalam melakukan suatu aktivitas kerja, baik di dalam perusahaan maupun sebuah organisasi. Salah satu permasalahan besar dalam dunia kerja di Indonesia adalah tingkat pengangguran yang tinggi, permasalahan ini timbul akibat dari lapangan pekerjaan yang tersedia tidak sebanding dengan jumlah pencari kerja dan ketimpangan antara keahlianyang dibutuhkan oleh perusahaan dengan keahlian yang dimiliki oleh para pencari kerja. Kedua hal tersebut sudah menjadi permasalahan menahun yang terus menerus tidak terselesaikan, hal ini memunculkan rasa pesimis dan ketidaksiapan bagi calon pencari kerja.

Tak terkecuali siswa-siswi kelas XII Sekolah Menengah Kejuruan yang akan memasuki dunia kerja, meskipun siswa-siswi SMK telah mempelajari satu keahlianyang disesuaikan dengan jenis-jenis lapangan kerja secara khusus. Namun berdasarkan data Badan Pusat Statistik yang dihimpun oleh media online tempo.co (22/08/2020), lulusan SMK menjadi urutan pertama yang menduduki tingkat pengangguran tertinggi dengan persentase sebesar 8,49\% berdasarkan tingkat pendidikan yang ditamatkan. Data lain mengatakan, bahwa lulusan SMK yang menganggur di Indonesia pertahunnya selalu mengalami peningkatan yang cukup tinggi dari 183.629 lulusan tahun 2018 menjadi 409.890 lulusan pada tahun 2019. Di Karawang, SMA/SMK setiap tahun melahirkan sekitar 24 ribu orang lulusan baru, hal tersebut berdasarkan data yang diungkapkan oleh Ahmad Suroto selaku kepala disnakertran, Karawang pada Badan Pusat S. Selain itu, data disnaker mengungkapkan bahwa lapangan kerja di Karawang hanya mampu menyerap 14 ribu orang setiap tahun, sehingga 10 ribu orang yang lain menjadi pengganguran. Salah satu upaya yang dilakukan oleh pemerintah kabupaten Karawang untuk menekan angka peningkatan pengangguran adalah mengkoordinasi 940 perusahaan yang ada untuk bekerja sama dengan 9 SMK yang ada di Karawang agar tercipta dunia kerja menjadi lebih ramah. Lulusan SMK dianggap sebagai lulusan siap pakai untuk perusahaan, karena telah memiliki keahlian-keahlian dasar dan pernah melakukan kerja praktek langsung (magang).

Sekolah Menengah Kejuruan menurut Peraturan Pemerintah Republik Indonesia (PP RI) No. 29 Tahun 1990 tentang pendidikan menengah kejuruan pasal 1 mengatakan bahwa pendidikan menengah kejuruan merupakan pendidikan pada jenjang menengah yang mengutamakan pengembangan kemampuan siswa untuk melaksanakan jenis pekerjaan tertentu. Maka siswa SMK seharusnya memiliki pengetahuan yang luas mengenai dunia kerja karena sasaran lulusan SMK adalah untuk bekerja sesuai bidang kejuruan yang ditekuninya sehingga ketimpangan antara keahlian yang dibutuhkan perusahaan dan keahlian yang dimiliki calon pencari kerja dapat diminimalisir. Salah satu SMK yang ada di Karawang adalah SMK IPTEK Sanggabuana Pangkalan, sekolahan ini berada di daearah pangkalan yang sedikit jauh dari pusat industri Karawang. Permasalahan yang ditemukan pada sekolah ini adalah siswa-siswi kelas XII yang tidak siap menghadapi dunia kerja dan merasa pesimis, karena merasa keahlian khusus yang diberikan oleh sekolah tidak cukup mampu membantu siswa-siswi kelas XII ini untuk menembus dunia kerja di Karawang. Hal lainnya, karena lulusan-lulusan terdahulu banyak yang bekerja tidak sesuai dengan bidang keahlian yang di pelajari sehingga menurunkan tingkat optimisme siswa-siswi XII dalam menghadapi dunia kerja yang keras. 
Ibu Maryam salah satu guru di sekolah ini menjabarkan data Bursa Kerja Khusus (BKK) yang diadakan oleh SMK IPTEK, bahwa kompetensi keahlian teknik mesin tahun ajaran 2016/2017 dengan jumlah lulusan 57 siswa dari 2 kelas dengan jurusan teknis mesin . Terdapat 11 siswa (20\%) melanjutkan perguruan tinggi, 20 siswa (35\%) bekerja diberbagai sektor, 1 siswa (2\%) wirausaha dan sisanya 25 siswa $(45 \%)$ ada yang menikah menganggur dan menunggu lowongan pekerjaan. Persentase lulusan yang mampu menembus dunia kerja cukup rendah, sehingga hal tersebutlah yang menurukan optimisme siswa-siswi kelas XII SMK IPTEK Sanggabuana Pangkalan.

Seligman (dalam Golmen, 2009) mengatakan optimisme adalah suatu pandangan secara menyeluruh, melihat hal yang baik, berpikir positif dan mudah memberikan makna bagi diri sendiri, individu yang optimis mampu menghasilkan suatu yang lebih baik dari dalam dirinya sehingga kegagalan yang akan memotivasi individu untuk tetap berusaha mencoba kembali untuk tidak gagal dikemudian. Sehingga apabila rasa optimisme yang tinggi dapat dimiliki oleh setiap siswa, maka siswa yang akan menjadi pencari kerja baru tidak akan mudah menyerah saat menghadapi permasalahan-permasalahan umum yang sering terjadi di dunia kerja. Optimisme pun dapat membuat langkah-langkah siswa-siswi ini menjadi lebih ringan dalam mencari pekerjaan karena memandang segala sesuatu secara positif dan tidak berkutat dalam ketidakmampuan yang dimiliki namun meningkatkan kemampuan yang ada agar tidak kembali gagal. Optimisme melahirkan suatu keyakinan dari keyakinan memunculkan suatu kesadaran dari kesadaran melahirkan amaliah dan dari amaliah akan tercapainya hasil-hasil yang diharapkan. Namun optimisme yang membabi butapun tanpa diimbangi oleh efikasi diri yang tinggi tidak dapat membuat individu bergerak kearah yang baik.

Pengaruh efikasi diri terhadap optimisme menghadapi dunia kerja merupakan suatu keyakinan diri bahwa hubungan seseorang dan lingkungannya dipengaruhi oleh penilaian dan penyesuian diri dan secara potensial yang dapat mengurangi stres dan adaptasi seseorang terhadap lingkungan (Lazarus, 2010). Siswa-siswi yang memiliki efikasi diri tinggi akan memiliki rasa yakin dan optimisme untuk bertahan dan juga mampu untuk memahami keinginan maupun kebutuhannya serta mampu memahami orang lain dengan baik dalam hal ini perusahaan atau organisasi selaku pencipta dunia kerja. Jess Feist dan Gregory J. Feist, (2011) mengatakan efikasi diri adalah keyakinan atau kepercayaan seseorang bahwa ia dapat melakukan suatu perilaku yang akan menghasilkan apa yang diinginkan dalam situasi yang khusus. Efikasi diri yang tinggi dapat membantu individu menuju tujuan yang telah ditetapakan secara lebih mudah. Sementara individu dengan efikasi diri rendah akan menyebabkan meningkatnya kecemasan dan perilaku menghindar, sehingga performa seorang individu secara umum akan meningkat saat ia memiliki efikasi diri yang tinggi.

Hal tersebut sesuai dengan hasil penelitian yang dilakukan oleh Purningsih, dkk., (2016) yang menunjukan bahwa adanya pengaruh antara varibel efikasi diri dengan optimisme menghadapi dunia kerja. Pernyataan lain yang memperkuat argumentasi diatasa adalah deskripsi teoritis yang dikemukakan oleh Bandura (dalam Purningsih, dkk., 2016) mengatakan bahwa efikasi diri mempengaruhi pilihan aktivitas usaha seseorang dalam menyelesaikan masalah yang dihadapi. Seseorang dengan efikasi diri tinggi akan mampu merencankan dan melaksanakan tindakan yang mengarah pada pencapaian tujuan. 
Optimisme dan Efikasi diri yang tinggi amat diperlukan bagi siswa-siswi kelas XII karena akan memasuki dunia baru yaitu dunia kerja. Dunia baru ini tentu memiliki permasalahan dan tantangan yang berbeda dengan dunia sekolah. Optimisme dan efikasi diri menjadi bekal secara internal selain keahlian yang telah dipelajadi di sekolah untuk siswa-siswi yang akan mencari pekerjaan. Di dalam dunia kerja, lapangan pekerjaan yang tersedia umumnya sedikit sehinga daya saing antar pencari kerja semakin ketat terutama beberapa bidang. Mayoritas siswa-siwi SMK setelah lulus mereka ingin bekerja sesuai dengan keahlian yang dipelajari selama sekolah yaitu beberapa keahlian dasar yang dimiliki, fisik yang terlatih, serta kemampuan dalam nilai akademiknya. Optimisme yang tinggi akan membantu siswa mengontrol kemampuan dan menerima kejadian dalam lingkungan secara positif.

Contoh permasalahan yang akan dihadapi oleh siswa-siswi kelas XII ketika memasuki dunia kerja adalah kesuliatan mencari lapangan pekerjaan dan informasi yang minim mengenai dunia kerja. Siswa-siswi yang optimis dan memiliki efikasi diri yang tinggi tidak akan hanya menunggu informasi dan menyalahkan pihak-pihak eksternal yang tidak memberikan informasi. Namun mencari lapangan pekerjaan secara mandiri menggunakan seluruh kemampuan yang dimiliki agar segera mendapatkan pekerjaan seperti memaksimalkan media sosial beberapa perusahaan yang memberikan informasi mengenai rekruitmen, mengikuti program pelatihan yang diadakan pemerintah atau mendatangi beberapa lembaga menyalur tenaga kerja. Optimisme dan efikasi diri yang tinggi mampu mendorong seseorang untuk melakukan banyak hal dengan memaksimalkan kemampuan yang dimiliki.

Sarapiro (dalam Ghufron \& Risnawati, 2011) mengatakan yang perlu diperhatikan meraih kesuksesan siswa harus bisa meningkatkan efikasi dirinya secara penuh serta dukungan sosial yang yang diberikan terhadap siswa, meski sulit mencari kerja di jaman sekarang dan harus memiliki jaminan tak cukup hanya dalam bidang akademik saja, karena banyak orang-orang yang tak memperdulikan akan keadaan fisik atau kualifikasi per individu yang kurang memenuhi syarat dalam kualifikasi standar penerimaan karyawan baru. Dukungan sosial sangat penting juga diberikan terhadap siswa yang akan menghadapi dunia kerja dengan adanya kenyamana, keperdulian, harga diri atau bantuan yang diterima seseorang dari orang lain atau kelompok lain dan dukungan yang di berikan dapat membatu individu untuk memecahkan masalah serta mengurangi rasa emosi negatif dari masalah yang terjadi (Sarafino, 2011). Serta hubungan non professional, yakni bersumber dari orangorang terdekat seperti teman, keluarga maupun relasi Gottlieb (dalam Ristianti, 2011).

Berdasarkan penelitian yang dilakukan Ernawati (2017) mengenai optimisme mengungkapkan hasil adanya dukungan sosial dan efikasi diri terhadap optimisme menghadapi dunia kerja. Bahwa efikasi diri juga berpengaruh terhadap optimisme menghadapi dunia kerja dengan adanya tingkat kepercayaan diri yang tinggi dan bisa mengambil keputusan dengan baik Sukmadinata (dalam Ernawati, 2017). Dukungan sosial yang sangat mempengaruhi lingkungan sekitar yang menuntut untuk setelah lulus sekolah harus bekerja dengan bekal optimis dalam diri perindividu keyakinan yang siswa miliki untuk bisa bekerja di perusahaan-perusahaan yang mereka inginkan. Bahwa dukungan sosial merupakan kenyamanan secara fisik dan psikologis yang diberikan oleh teman atau keluarga, dukungan sosial juga dapat 
dilihat dari banyaknya teman-teman dekat di lingkungan sekitar (Baron \& Byrne, dalam Mulyana, dkk., 2015).

Berdasarkan pada uraian latar belakang penelitian di atas, maka perumusan masalah dalam penelitian ini adalah apakah ada pengaruh efikasi diri dan dukungan sosial terhadap optimisme menghadapi dunia kerja. Untuk menjawab rumusan masalah tersebut maka penulis tertarik akan penelitian dengan judul, "pengaruh efikasi diri dan dukungan sosial terhadap optimisme menghadapi dunia kerja siswa kelas XII SMK IPTEK Sanggabuana Pangkalan Karawang”.

\section{LANDASAN TEORI}

\section{Efikasi Diri}

Definisi dari efikasi diri terus berkembang menurut Bandura (dalam Suseno, 2012) mengartikan efikasi diri adalah keyakinan seorang individu mengenal kemampuannya dalam mengorganisasi dan menyelesaikan suatu tugas yang diperlukan untuk mencapai hasil tertentu serta efikasi diri mengacu pada keyakinan sejauh mana individu memperkirakan kemampuan dirinya dalam menyelesaikan tugas atau melakukan suatu tugas yang diperlukan untuk mencapai suatu hasil tertentu.

Menurut Bandura (dalam Suseno, 2012) menjelaskan efikasi diri terdiri dari beberapa dimensi.

1. Tingkat (level)

Dimensi ini memiliki implikasi terhadap pemilihan tingkah laku yang dirasa mampu dilakukannya dan menghindari tingkah laku yang berada diluar batas kemampuan yang dirasakannya.

2. Keyakinan (strength)

Dimensi ini biasanya berkaitan langsung dengan dimensi level, yaitu makin tinggi level taraf kesulitan tugas, makin lemah keyakinan yang dirasakan untuk menyelesaikannya.

\section{Generalisasi (geneality)}

Berkaitan dengan luas bidang tingkah laku yang dimana individu merasa yakin akan kemampuannya.

Bandura (dalam Suseno, 2012), mengemukakan bahwa tingkat efikasi diri dipengaruhi beberapa faktor, yaitu:

a. Sifat tugas yang dihadapi

Semakin kompleks dan sulit suatu tugas bagi seseorang maka semakin besar keraguan terhadap kemampuannya.

b. Intensif eksternal

Adanya insentif berupa hadiah (reward) dari orang lain untuk merefleksikan keberhasilan individu dalam menguasai atau melaksanakan suatu tugas akan meningkatkan efikasi dirinya. 
c. Status seseorang dalam lingkungan.

Seseorang yang memiliki status sosial lebih tinggi akan memiliki tingkat efikasi diri yang tinggi pula dibandingkan seseorang yang berstatus sosial lebih rendah.

d. Informasi tentang kemampuan diri.

Efikasi diri akan meningkat jika seseorang mendapatkan informasi yang positif tentang dirinya.

\section{Dukungan Sosial}

Menurut Sarafino (dalam Kumalasari \& Ahyani, 2012) dukungan sosial (social support) adalah bentuk perhatian, penghargaan, semangat, penerimaan, maupun pertolongan dari orang-orang terdekat, antara lain seperti orang tua, saudara, guru, teman maupun orang lain dengan tujuan membantu seseorang saat mengalami permasalahan.

Menurut Sarafino (dalam Kumalasari \& Ahyani, 2012) mengemukakan dukungan sosial meliputi empat aspek, yaitu:

a. Dukungan Emosional

Dukungan ini merupakan penyampaian empati, kepedulian, perhatian, penghargaan yang positif, dan keyakinan terhadap seseorang.

b. Dukungan penghargaan.

Dukungan ini suatu bentuk dukungan yang berupa ungkapan yang diberikan oleh orang tua, guru bahkan orang disekelilingnya dalam hal membantu membangun kompetensi dan mengembangkan harga diri.

c. Dukungan instrumental.

Dukungan ini merupakan dukungan yang menyediakan saran untuk mempermudah dalam membantu orang lain yang berwujudkan dalam bentuk bantuan material atau jasa.

d. Dukungan informasi.

Dukungan ini meliputi pemberian nasehat, saran atau umpan balik kepada inividu dukungan ini biasanya diperoleh dari keluarga, sahabat dan rekan kerja.

Menurut Myers (2012), ada 4 (empat) faktor yang menyebabkan terbentuknya dukungan sosial, diantaranya yaitu:

a. Empati

Dimana kemampuan dan kecenderungan berempati pada individu lain merupakan motif utama dalam tingkah laku yang mendorong individu.

b. Norma

Diterima seseorang selama pertumbuhan dan perkembangan pribadi dari pengalaman bersosialisasi, mengarahkan seseorang untuk bertingkah laku secara tepat dan mengharuskan individu untuk menjalankan kewajiban dalam kehidupan sosial. 


\section{c. Pertukaran Sosial.}

Ekonomi sosial yaitu adanya penghargaan dan ganti rugi dengan cara memberi dan menerima.

\section{d. Sosiologi}

Teori ini merupakan aplikasi prinsip evolusi, dimana perilaku menolong dianggap lebih menguntungkan jika dilakukan pada individu yang memiliki hubungan darah sehingga keturunannya tetap bertahan daripada menolong individu lain yang bisa menghabiskan waktu dan tenaga.

\section{Optimisme}

Seligman (dalam Ghufron \& Rini, 2010) menyatakan optimisme adalah suatu pandangan secara menyeluruh, melihat hal yang baik, berpikir positif dan mudah memberikan makna bagi diri.

Menurut Seligman (dalam Gufron \& Rini, 2010) menyatakan bahwa terdapat beberapa aspek dalam optimisme, yaitu:

\section{a. Permanence}

Aspek permanence memiliki makna bahwa seseorang menyikapi suatu peristiwa buruk maupun baik memiliki penyebab yang menetap maupun sementara.

b. Pervasiveness

Aspek pervasiveness memiliki makna bahwa seseorang yang optimis akan menelusuri suatu penyebab permasalahan hingga akar-akarnya.

\section{c. Personalization}

Aspek personalization menjelaskan setiap penyebab dari suatu kegagalan berasal dari internal (diri individu) atau pun dari eksternal (orang lain).

Seligman (2008) menjelaskan bahwa ada beberapa faktor yang dapat mempengaruhi optimisme:

a. Dukungan Sosial.

Adanya dukungan yang cukup dapat membuat individu lebih optimis karena merasa yakin bahwa bantuan akan selalu tersedia bila dibutuhkan.

b. Kepercayaan diri.

Individu yang yang memiliki keyakinan yang tinggi dengan apa yang ada pada dirinya, serta yakin dengan kemampuannya akan mempunyai optimis yang tinggi.

c. Harga diri.

Individu dengan harga diri tinggi selalu termotivasi untuk menjaga pandangan yang positif tentang dirinya dan mencari aset-aset personal yang dapat mengimbangi kegagalan, sehingga selalu berusaha lebih keras dan lebih baik pada usaha-usaha berikutnya. 


\section{METODE PENELITIAN}

Metode yang digunakan dalam penelitian ini adalah metode penelitian kuantitatif. Teknik pengambilan sampel dalam penelitin ini yaitu menggunakan teknik nonprobability sampling. Sampel yang diperoleh lewat pengambilan sampel dengan sampling kuota. Sampling kuota adalah teknik untuk menentukan sampel dari populasi yang mempunyai kakarkteristik yang sesuai sampai jumlah kuota yang diinginkan terpenuhi (Sugiyono, 2016). Populasi dari pengumpulan data yang digunakan oleh peneliti menggunakan kuesioner. Alat ukur penelitian menggunakan skala efikasi diri, skala dukungan sosial dan skala optimisme. Berdasarkan data yang diperoleh dari SMK IPTEK Sanggabuana Pangkalan Karawang dengan jumlah populasi 270 siswa/siswi kelas XII. Jumlah penentuan sampel yang digunakan berdasrkan tabel Isaac dan Micheal dengan tingkat kesalahan 5\% maka diperoleh sampel sebanyak 152 siswa/siswi.

\section{HASIL DAN PEMBAHASAN}

\section{Tests of Normality}

\begin{tabular}{lr|r|r|r|r|r} 
& \multicolumn{3}{c|}{ Kolmogorov-Smirnov $^{a}$} & \multicolumn{3}{|c}{ Shapiro-Wilk } \\
& Statistic & \multicolumn{1}{c|}{ Df } & Sig. & Statistic & Df & \multicolumn{1}{c}{ Sig. } \\
\hline TOTALED & 0,102 & 152 & 0,001 & 0,971 & 152 & 0,003 \\
\hline TOTALDS & 0,069 & 152 & 0,075 & 0,989 & 152 & 0,303 \\
TOTALOP & 0,075 & 152 & 0,034 & 0,970 & 152 & 0,002
\end{tabular}

a. Lilliefors Significance Correction

Berdasarkan hasil uji normalitas menunjukan sinifikan sefikasi diri menunjukan taraf signifikansi $0,001(\mathrm{p}<0,05)$ yang artinya tidak normal, taraf signifikansi dukungan sosial sebesar 0,075 lebih dari $0,05(\mathrm{p}>0,05)$ yang artinya normal dan optimisme menghadapi dunia kerja menunjukan taraf signifikansi 0,034 $(\mathrm{p}<0,05)$ yang artinya tidak normal.

\begin{tabular}{|c|c|c|c|c|c|c|c|}
\hline & & & INOVA $T$ & & & & \\
\hline & & & $\begin{array}{l}\text { Sum of } \\
\text { Squares }\end{array}$ & $\mathrm{df}$ & $\begin{array}{l}\text { Mean } \\
\text { Square }\end{array}$ & $\mathrm{F}$ & Sig. \\
\hline TOTALOP & Between & (Combined) & 5953,222 & 31 & 192,039 & 1,374 & 0,115 \\
\hline & Groups & Linearity & 871,829 & 1 & 871,829 & 6,239 & 0,014 \\
\hline & & $\begin{array}{l}\text { Deviation } \\
\text { from } \\
\text { Linearity }\end{array}$ & 5081,393 & 30 & 169,380 & 1,212 & 0,231 \\
\hline & Within C & ups & 16768,989 & 120 & 139,742 & & \\
\hline & Total & & 22722,211 & 151 & & & \\
\hline
\end{tabular}


Berdasarkan hasil uji linearitas diketahui bahwa variabel efikasi diri terhadap variabel optimisme menghadapi dunia kerja memiliki nilai Signifikan sebesar 0,014 $<0,05$ maka dapat dikatakan hubungan antara dua variabel ini adalah linear. Serta varibel dukungan sosial terhadap variabel optimisme menghadapi dunia kerja memiliki nilai signifikan sebesar $0,000<0,05$ maka dapat dikatakan hubungan antara dua variabel ini adalah linear.

\begin{tabular}{|c|c|c|c|c|c|c|}
\hline \multicolumn{7}{|c|}{ ANOVA $^{a}$} \\
\hline & Model & $\begin{array}{l}\text { Sum of } \\
\text { Squares }\end{array}$ & Df & $\begin{array}{l}\text { Mean } \\
\text { Square }\end{array}$ & $\mathrm{F}$ & Sig. \\
\hline \multirow[t]{3}{*}{1} & Regression & 11658,652 & 2 & 5829,326 & 78,507 &, 000 \\
\hline & Residual & 11063,559 & 149 & 74,252 & & \\
\hline & Total & 22722,211 & 151 & & & \\
\hline
\end{tabular}

Berdasarkan tabel 4.7 di atas bahwa dilakukan uji simultan yang menunjukan nilai Sig. F 0,000<0,05 maka hipotesis optimisme menghadapi dunia kerja diterima. Sehingga dapat disimpulkan bahwa Efikasi diri dan dukungan sosial secara bersamasama berpengaruh terhadap optimisme menghadapi dunia kerja siswa kelas XII SMK IPTEK Sanggabuana Pangkalan Karawang.

\section{Coefficients $^{\mathrm{a}}$}

\begin{tabular}{|c|c|c|c|c|c|c|}
\hline \multirow{2}{*}{\multicolumn{2}{|c|}{ Model }} & \multicolumn{2}{|c|}{$\begin{array}{c}\text { Unstandardized } \\
\text { Coefficients }\end{array}$} & \multirow{2}{*}{$\begin{array}{c}\text { Standardized } \\
\text { Coefficients }\end{array}$} & \multirow[b]{2}{*}{$\mathrm{t}$} & \multirow[b]{2}{*}{ Sig. } \\
\hline & & B & Std. Error & & & \\
\hline \multirow[t]{3}{*}{1} & (Constant) & 13,478 & 10,873 & & 1,240 & 0,217 \\
\hline & TOTALED & 0,071 & 0,120 & 0,034 & 0,594 & 0,554 \\
\hline & TOTALDS & 0,922 & 0,076 & 0,709 & 12,207 & 0,000 \\
\hline
\end{tabular}

Berdasarkan Tabel 4.8 bahwa nilai Sig. T Untuk variabel efikasi diri adalah sebesar 0,554 > 0,05 maka dari itu hipotesis efikasi diri ditolak, artinya variabel efikasi diri tidak berpengaruh signifikan terhadap optimisme menghadapi dunia kerja. Selanjutnya untuk variabel dukungan sosial menunjukan nilai Sig. Sebesar $0,000<0,05$ maka dari hipotesis dukungan sosial diterima, artinya variabel dukungan sosial berpengaruh signifikan terhadap optimisme menghadapi dunia kerja.

\section{Model Summary}

\begin{tabular}{c|c|c|c|c} 
Model & $\mathrm{R}$ & $\begin{array}{c}\mathrm{R} \\
\text { Square }\end{array}$ & $\begin{array}{c}\text { Adjusted } \\
R \text { Square }\end{array}$ & $\begin{array}{c}\text { Std. Error of the } \\
\text { Estimate }\end{array}$ \\
\hline &, $716^{\mathrm{a}}$ & 0,513 & 0,506 & 8,622 \\
\hline
\end{tabular}


Hasil tersebut mengartikan bahwa besarnya pengaruh yang disumbangkan oleh variabel efikasi diri dan dukungan sosial terhadap optimisme menghadapi dunia kerja adalah sebesar $\mathrm{R}^{2}=51,3 \%$ sedangkan sisanya $48,7 \%$ pada sampel penelitian siswa kelas XII SMK IPTEK dipengaruhi oleh variabel lain.

\begin{tabular}{ccc}
\hline Efikasi Diri & Frequency & Percant \\
\hline Rendah & 64 & 42,1 \\
\hline
\end{tabular}

\begin{tabular}{ccc}
\hline Dukungan Sosial & Frequency & Percant \\
\hline Tinggi & 72 & 47,4
\end{tabular}

Berdasarkan uji katagorisasi menunjukan bahwa responden memiliki efikasi diri, dukungan sosial dan optimisme. yang didominasikan oleh katagori rendah yaitu $42,1 \%$ (efikasi diri), tinggi yaitu 47,4\% (dukungan sosial), tinggi yaitu 48,1\% (optimisme).

\section{KESIMPULAN}

Berdasarkan hasil analisis data dan pembahasan di atas, maka peneliti dapat menyimpulkan bahwa. Tidak terdapat pengaruh efikasi diri terhadap optimisme menghadapi duni kerja siswa kelas XII SMK IPTEK, yaitu dibuktikan dengan nilai signifikan variabel efikasi diri lebih besar dengan nilai 0,554>0,05.

\begin{tabular}{ccc}
\hline Optimisme & Frequency & Percent \\
\hline Tinggi & 73 & 48,1 \\
\hline
\end{tabular}

Terdapat pengaruh dukungan sosial terhadap optimisme menghadapi duni kerja siswa kelas XII SMK IPTEK, yaitu dibuktikan dengan nilai signifikan variabel dukungan sosial lebih kecil dengan nilai $0,000<0,05$. Efikasi diri dan dukungan sosial secara bersama-sama berpengaruh terhadap optimisme menghadapi duni kerja siswa kelas XII SMK IPTEK, yaitu dibuktikan dengan nilai signifikan 0,000 0,05.

\section{DAFTAR PUSTAKA}

Arikunto, Suharsimi. (2010). Prosedur penelitian Suatu Pendekatan Praktik. Yogyakarta: Rineka Cipta.

Apollo dan Cahyadi. (2012). Dukungan Sosial Keluarga dan Penyesuaian Diri. Jurnal Widya Warta No.02 Vol.0854-1981.

Ahmad Suroto, Badan Pusat Statistik (BPS) 2019. Karawang 41312 Jawa Barat.

Bandura, (1997). Self Efficacy: The Exercize Of Control, New York: W. H. Freeman and Company. Program Studi Psikologi Fakultas Ilmu Kesehatan Universitas Sahid Surakarta. Vol. 11, No 2. 
Ernawati, Selly. (2017). Pengaruh Self-Efficacy dan Dukungan Sosial Terhadap Optimisme Menghadapi Dunia Kerja Kelas XII SMK Lamongan. Universitas Islam Negeri Maulana Malik Ibrahim Malang. Skripsi tidak diterbitkan.

Feist, J \& Feist, G. J. (2010). Teori Kepribadian, edisi 7. Jakarta: Salemba Humanika.

Ghufron, M \& Nur Rini Risnawati (2010). Teori-Teori Psikologi. Yogyakarta: ArRuzz Media.

King A Laura, (2012). Psikologi Umum (Sebuah Pandangan Apresiatif). Jakarta : Salemba Humanika.

Kumalasari \& Ahyani (2012) Pengaruh Antara Dukungan Sosial dengan Efikasi Diri Remaja di Panti Asuhan. Jurnal Psikologi Pitutur Volume 1 No.1 Juni 2012,21,31. Naskah Publikasi.

Myers, D.(2012) Psikologi Sosial Jilid 2. Ahli Bahasa: Aliya Tusyani. Jakarta: Salemba Humanika.

Lazarus, (2010). Emotion and Adaptation. New York: Oxford University Press.

Omrod, Jeans Ellis. (2009) psikologi Pendidikan Membantu Siswa tumbuh Dan Berkembang. Jakarta: Erlangga.

Robbins, Wulandari, (2013). Perilaku Organisasi. Edisi 12 Buku 1, Salemba Empat: Jakarta.

Robert, Albert R dan Gilbert J, (2009). Buku Pintar Pekerja Sosial - Jilid 2. Jakarta: Gunung Mulia.

Sarafino, Edward P., Timoty W. Smith (2011). Healt Psyhology Biopsychosocial Interaction Seventh Editation. New York: John Wiley \& Sons, Inc.

Sarason, I. G. (1983) dalam Purba (2007). Assessing Social Support: The Social Support Questionnaire. Journal of Personality and Social Psyhology. Vol 44.

Seligman,(2008). The Optimisme Child. Bandung: PT. Mizan

Siregar, (2013). Statistik Parametrik untuk Penelitian Kuantitatif. Jakarta: PT. Bumi Aksara.

Sugiyono. (2016). Metode Penelitian Kuantitatif, Kualitatif dan R\&D. Bandung: Alfabeta.

Suseno, (2012). Pengaruh Pelatihan Komunikasi Interpersonal Terhadap Efikasi Diri Sebagai Pelatih Pada Siswa. Cetakan ke 1. Jakarta Pusat: Kementrian Agama Republik Indonesia. 